\title{
08-Inorganic and Mineralogical Crystallography
}

\section{MS-08.01.08 \\ THE RELATIONSHIP BETWEEN CRYSTAL STRUCTURE AND PHYSICAL PROPERTIES IN INORGANIC CRYSTALS}

P.A.Thomas, Department of Physics, University of Warwick, COVENTRY, CV4 7AL.

There is an increasing search for new crystalline materials for many applications. Therefore, the understanding of the relationship between crystal structure and physical properties is becoming ever more relevant, particularly because it forms the scientific foundation for the prediction of the new technologically-important crystals of the future

In this talk, a review will be given of the relationship between physical properties and crystal structure. We will consider how analysis of crystal structure can be of benefit to materials research and technology and therefore, how the crystallographer can also benefit from this relationchin iho major emphasis will be placed on non-centrosymmetric crystal structures and the relation of these with polar or chiral physical properties such as the piezoelectric and electrooptic effects or optical rotation, but we will also consider the much-neglected relationship between structure and simple linear properties such as refractive index. Some examples of this from our own research on erystals of the potassium titanyl phosphate, $\mathrm{KTiOPO}_{4}$, family of nonlinear optical crystals will be given; for cxample, the questions of how useful lasing ions can be introduced into $\mathrm{KTIOPO}_{4}$ itself and how the isostructural analogue $\mathrm{KTiOASO}_{4}$ can be modified so that it is useful for second-harmonic generation.

Further to the straight-forward relationship between structure and naturally-occurring physical properties in crystals, it is important to recognize the current emphasis on the modification of well-characterised and established crystals. These modifications produce subtly-altered materials that have been perfected for a given function. This has long been the case in the area of semiconductor research but these ideas are now spreading in an analogous way into the realms of optical materials and dielectrics. In particular, we shall discuss the phenomenon of periodic domain inversion in polar crystals and also address the growing phenomenon of composite materials that are designed to incorporate the desirable features of more than one component; for example, inorganic-organic composites for nonlinear optical and photoclectric applications will be described.

PS-08 01.09 THE ROLE OF LONE PAIR ELECTRONS IN THE BOND-VALENCE APPROACH FOR Sb(III)CHAICOGEN COMPOUNDS. By X. Wang* and F. Liebau, Mineralogisches Institui der Universität Kiel, Germany.

One of the basic assumptions of the bond-valence model is the valence sum rule: $V_{i}=\Sigma s_{i j}$ (1). Here, $V_{i}$ is the atomic valence of atom $i$ and $s_{i j}$ refers to the bond valences of the chemical bonds around atom $i$. The bond valence $s_{i j}$ is assumed to be a monotonic function of bond length $d_{i j}$ and can be approximated by the empirical equation $s_{i j}=\exp \left[\left(r_{0}-d_{i j}\right) / B\right](2)$, where $r_{0}$ and $B$ are bond valence parameters and can be calculated from (1) and (2) (Brown, I.D. 1992, Acta Cryst.B48,553-572). Assuming that $V_{i}$ is equal to the formal valence coxidation number), Brown and Altermatt (1985, Acta Cryst. B41, 244-247) found that for most bonds, $B$ can be set equal to $0.37 \dot{A}$. They tabulated $r_{0}$ for most of the common bonds. These $r_{0}$ are widely used and usually considered as constaits.
According to Brown (1992), in most cases, structures in which the bonding is distorted by electronic effects, as through the presence of lone pair electrons, do not violate the valence sum rule. However, during studies of Sb(III)-chaicogen compounds we found that for some accurately determined $\left[\mathrm{Sb}(\mathrm{III}) \mathrm{S}_{\mathrm{n}}\right]$ groups the sums of bond valences of the bonds around $\mathrm{Sb}$ (III) calculated from (2) are much higher than 3 (the formal valence of $\mathrm{Sb}$ ), if the bond valence parameters of Brown and Aitermatt (1985) are used. Further studies disclosed that for those $\left[\mathrm{Sb}\right.$ (III) $\left.X_{n}\right]$ groups with $X=S$, Se, which can be considered as $\left[\mathrm{SbX}_{3} \mathrm{E}\right]$ tetrahedra ( $E=$ electron lone pair) complemented by 0 to 4 additional $X$ ions with weaker $S b-X$ bonds, the calculated individual $r_{0}$ values are inversely correlated with the average of the $\mathrm{X}-\mathrm{Sb}-\mathrm{X}$ angles of the $\left[\mathrm{SbX}_{3} \mathrm{E}\right]$ tetrahedra (Fig.1) rather than being constant. Since so calculated $r_{0}$ is equal to the average bond length in a $\left[\mathrm{SbX}_{3}\right]^{3 \cdot}$ symmetrical trigonal pyramid, the fact that the solid squares representing the $\mathrm{X}-\mathrm{Sb}-\mathrm{X}$ bond angles and $\mathrm{Sb}-\mathrm{X}$ bond lengths (with tond valence 1.25 v.u.) of the symmetrical [Sb(V) $\left.\mathrm{X}_{4}\right]^{3}$ tetrahedra fall on the correlation trends in Fig.1, indicates that the effective valence of $\mathrm{Sb}$ of the $\left[\mathrm{SbX}_{3}\right]^{3-}$ pyramids approaches $1.25 \times 3=3.75$ v.u. as the average $\mathrm{X}-\mathrm{Sb}-\mathrm{X}$ angle increases Therefore, if we treat $\mathrm{Sb}(\mathrm{III})$ in $\left[\mathrm{SbX}_{3}\right]^{3 \cdot}$ pyramids as [Sb(V)E] and.E as an anion, then $S b(V)-E$ has a "bond" valence between 2 and 1.25 v.u. depending on the $X-S b-X$ angles, which might be considered as a measure of $s p^{3}$ hybridization.

A publication on semi-quantitative calculation of effective valences of Sb(III) in chalcogenides is in preparation.

Support from the DFG is gratefully acknowledged.

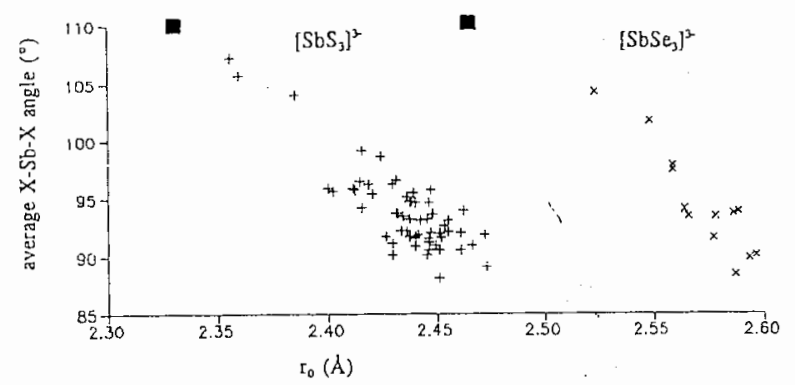

Fig. 1 Correlation between $r_{0}$ and average $\mathrm{X}-\mathrm{Sb}-\mathrm{X}$ angles of $\left[\mathrm{SbX}_{3}\right]^{3-}$ pyramids. For $\left[\mathrm{Sb}(\mathrm{V}) \mathrm{X}_{4}\right]^{3-}$ tetrahedra the average experimental $\mathrm{Sb}-\mathrm{X}$ bond lengths are plotted instead of $r_{o}$ and are represented by solid squares.

PS-08.01.10THE CRYSTAL STRUCTURE OF $\mathrm{Ag}_{3} \mathrm{Cu}_{12} \mathrm{Y}_{5}, \mathrm{~A}$ NEW TERNARY COMPOUND.BY L.M. Zeng, D.X.Li and Y.H.Zhuang, Department of Physics, Guangxi University, Nanning 530004 , China

A new ternary compound has been found in our recent investigation of the $500^{\circ} \mathrm{C}$ isothermal scetion of $\mathrm{Ag}-\mathrm{Cu}-\mathrm{Y}$ system. The new phase, which is $\mathrm{Ag}_{3} \mathrm{Cu}_{12} \mathrm{Y}_{5}$, has a limited solid solubility.The compositional range is $23-27 \mathrm{at} \% \mathrm{Y}, 9-19 \mathrm{at} . \% \mathrm{Ag}$ and $68-54 a \mathrm{a}, 1 \% \mathrm{Cu}$. The structure of the compound $\mathrm{Ag}_{3} \mathrm{Cu}_{12} \mathrm{Y}_{5}$ was determined by $X$-ray powder diffraction data $(\mathrm{Cu} \mathrm{K} \alpha$ radiation, $\lambda=1.54178 \AA$ ). The ncw phase has a cubic structure of $\beta-\mathrm{Mn}\left(\right.$ ( 13) iype with $\mathrm{a}=7.127(4) \AA$ at $25^{\circ} \mathrm{C}$. The space group is $\mathrm{O}^{7}-\mathrm{P} 4,32$ with $\mathrm{V}=362.0(7) \AA^{3}, \mathrm{Dx}=7.02 \mathrm{gcm}^{-3}$. Each unit cell 